\title{
Research on the Relationship between Industry Waste Water Pollution and Economic Growth of Hubei Province Based on SVAR Model
}

\author{
Luo Juan \\ College of Mathematics and Computer Science, Wuhan Textile University, Wuhan, 430073,China. \\ email:Iuojuan801128@163.com.
}

Keywords: Economic Growth, Industry Waste Water Pollution, SVAR model

\begin{abstract}
In this paper, we analyze the data of economic growth and industry waste water pollution from 2000 to 2014 in Hubei Province, then we built SVAR model to investigate the relationship between economic growth and industry waste water pollution. The results show that there is a long-term dynamic relationship between economic growth and industry waste water pollution, and the contribution rate of economic growth to industry waste water pollution is about $70 \%$. The government need to adjust the industrial structure reasonably and change the way of economic growth to promote the harmonious development of the economy and the environment.
\end{abstract}

\section{Introduction}

Hubei Province is an important city in the middle of China. [1] With the strategy of promoting the rise of the central region in 2006, Hubei Province is facing unprecedented opportunities for accelerating development. In recent years, the total GDP of Hubei province is in the process of rising, and the growth of GDP depends mainly on the second industry. [2] From the statistical data of these years, the manufacturing industry has been leading, followed by the manufacturing of transportation equipment, the smelting of black metal, and the increasing production of electricity and coal gas. The destruction of environment by traditional industrialization gradually influences the sustainable development of Hubei's economy. [3] The environmental quality and environmental balance caused by environmental pollution are increasingly becoming the key factors that restrict sustained economic growth. [4] This requires us to do research on the relationship between economy and environment with the help of mathematical models. In this paper, we mainly collect the economic data and industry waste water pollution data from2000to2014 in Hubei Province, establish the SVAR model, and carry out an empirical analysis on its influence mechanism, so as to know more clearly the mutual influence between the man and provide reasonable suggestions for sustainable development.[5]

\section{Modeling principle}

VAR model is based on the statistical properties of data, the principle is using each endogenous variable as function of all endogenous variable lagging values to construct the model. It is usually used to predict the time series and analyze dynamic effects of random disturbance term on variable system, so as to explain the impact of various economic shocks on economic variables.

The mathematical expression of the VAR (p) model:

$\mathrm{y}_{\mathrm{t}}=\Phi_{1} \mathrm{y}_{\mathrm{t}-1}+\cdots+\Phi_{\mathrm{p}} \mathrm{y}_{\mathrm{t}-\mathrm{p}}+\varepsilon_{\mathrm{t}} t=1,2 \cdots T$ (1)

$\mathrm{y}_{\mathrm{t}}$ :column vector of $\mathrm{k}$ dimensional endogenous variable, $p$ : Lagged order

$\mathrm{T}$ : Number of samples, $\Phi_{1}, \cdots \Phi_{p}$ : Coefficient matrix to be estimated( $\mathrm{k} \times \mathrm{k}$ matrix $)$

$\varepsilon_{t}$ : Column vector of $\mathrm{k}$ dimensional variable, 
Let $\mathrm{L}$ is the Lag operator, $\Phi(\mathrm{L})=\mathrm{I}_{\mathrm{k}}-\Phi_{1} \mathrm{~L}-\Phi_{2} \mathrm{~L}^{2}-\ldots \Phi_{\mathrm{p}} \mathrm{L}^{\mathrm{P}}$ is the parameter matrix, formula (1) can be represented by a simple transformation: $\Phi(\mathrm{L}) \mathrm{y}_{\mathrm{t}}=\varepsilon_{\mathrm{t}}(2)$

Formula (2) can be represented by another form: $\mathrm{y}_{\mathrm{t}}=\Theta(\mathrm{L}) \varepsilon_{t}$

here $\Theta(\mathrm{L})=\Theta_{0}+\Theta_{1} \mathrm{~L}+\Theta_{2} \mathrm{~L}^{2}+. ., \quad \Theta_{0}=\mathrm{I}_{\mathrm{k}}$

There is no exact form of the current correlation of variables in VAR model, because the right of the model does not contain current value of endogenous variables, and the current relationship is hidden in the structure of the error term which is unexplained. Then we discuss the structure VAR model (SVAR) which contains the current relationship between the variables in the model.

The form of SVAR (p): $\mathrm{C}_{0} \mathrm{y}_{\mathrm{t}}=\Gamma_{1} \mathrm{y}_{\mathrm{t}-1}+\Gamma_{2} \mathrm{y}_{\mathrm{t}-2}+\cdots+\Gamma_{\mathrm{p}} \mathrm{y}_{\mathrm{t}-\mathrm{p}}+u_{t}(4)$

The above formula can also be written as: $\mathrm{y}_{\mathrm{t}}=\mathrm{D}(\mathrm{L}) \mathrm{u}_{t}$, (5)

Let $\mathrm{D}(\mathrm{L})=\mathrm{D}_{0}+\mathrm{D}_{1} \mathrm{~L}+\ldots+\mathrm{D}_{\mathrm{P}} \mathrm{L}^{\mathrm{P}}, \mathrm{D}_{0}=\mathrm{C}_{0}^{-1}$

We can get the typical SVAR model: $\Theta(L) \varepsilon_{\mathrm{t}}=\mathrm{D}(\mathrm{L}) \mathrm{u}_{\mathrm{t}}(6)$

Because of $\Theta_{0}=\mathrm{I}_{\mathrm{k}}$, then $\Theta_{0} \varepsilon_{\mathrm{t}}=\varepsilon_{\mathrm{t}}=\mathrm{D}_{0} \mathrm{u}_{\mathrm{t}}$, or $\mathrm{D}_{0}^{-1} \varepsilon_{\mathrm{t}}=\mathrm{u}_{\mathrm{t}}(7)$

If we take square both sides of the equation (7) and compute expectation, then $\Sigma=\mathrm{D}_{0} \mathrm{D}_{0}^{\prime}$.

So we can identify the SVAR model by applying constraints on $\mathrm{D}_{0}$.

More generally, assuming that A, Bare invertible matrix, let A left multiply (2), and we can obtain: $\mathrm{A} \Phi(\mathrm{L}) \mathrm{y}_{\mathrm{t}}=\mathrm{A} \varepsilon_{\mathrm{t}}(8)$

If $\mathrm{A} \varepsilon_{\mathrm{t}}=\mathrm{Bu}, \mathrm{E}\left(\mathrm{u}_{\mathrm{t}}\right)=0_{\mathrm{k}}, \mathrm{E}\left(\mathrm{u}_{\mathrm{t}} \mathrm{u}_{\mathrm{t}}^{\prime}\right)=\mathrm{I}_{\mathrm{K}}$, the model is called AB- SVAR model.

In particular, if let $\mathrm{A}=\mathrm{D}_{0}^{-1}, \mathrm{~B}=\mathrm{I}_{\mathrm{K}}$, then $\mathrm{A} \varepsilon_{\mathrm{t}}=\mathrm{Bu}_{\mathrm{t}}(9)$

So (9) can also be called the AB-SVAR model.

In many cases, the coefficients in each equation in the VAR or SVAR model are not the object of attention. The main reason is that there are many coefficient of the VAR model; on the other hand, every single coefficient reflects only a partial relation, and it is not able to capture the dynamic process of complex and comprehensive. We are interested the dynamic effect when an error term is changed or the model is affected by a certain impact. This method is called impulse response function (IRF).In addition, we can also use the variance contribution rate (RVC) to evaluate the influence of one variable's disturbance term on another variable.

In third part, we will first model SVAR based on VAR model by using the economic and environmental data, then we use the IRF to analysis the effect on the environment caused by of the impact of economy, and the effect on economy caused by the impact of the environment. Finally, we use RVC to analyze the contribution of economic shocks to environmental pollution.

\section{Empirical analysis}

\section{A. Index selection}

We mainly select environmental indicators in Hubei province from 2000 to 2014. Economic indicator: per capita GDP (PGDP), Environmental indicator: industrial wastewater water pollution (WWP). The above data are derived from the statistical yearbook of Hubei province.

\section{B. Evaluation steps}

According to the theoretical framework, we first establish the VAR model and the SVAR model, then analyze impulse response function and variance contribution rate. The software Eviews6.0 is used as a mathematical tool.

We first check the stability of the variable before using it by ADF test. We take the logarithm of the above data as lnWWP, lnPGDP, and calculate the first order difference, which is expressed as $\Delta \ln W W P, \quad \Delta \ln$ PGDP. We find that time series of $\ln W W P$ and $\ln P G D P$ are unstable, but the first 
order difference is stable, so we establish the VAR model of the first order differential. We analyze the order lag order is 3 selected by AIC criterion, and then we get the formula (10).

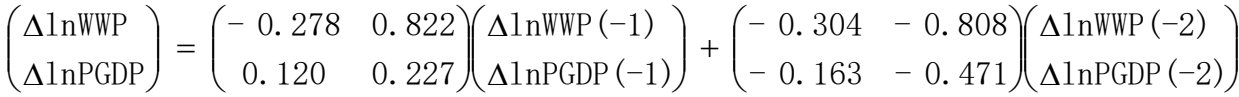

$$
\begin{aligned}
& +\left(\begin{array}{ll}
-0.849 & 1.140 \\
-0.786 & 0.863
\end{array}\right)\left(\begin{array}{l}
\Delta \ln W W P(-3) \\
\Delta \operatorname{lnPGDP}(-3)
\end{array}\right)+\left(\begin{array}{l}
-0.200 \\
0.062
\end{array}\right)+\left(\begin{array}{l}
\varepsilon_{11} \\
\varepsilon_{21}
\end{array}\right)
\end{aligned}
$$

In order to construct the SVAR model and analyze of impulse response function and the decomposition of variance, we need to test the stability of the model. The following figure 1 shows that the model is stable. Then we use the stable VAR model to build the SVAR model.

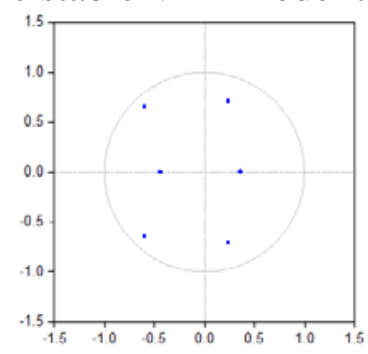

Figure 1Test of the VAR model stability

$$
\text { Let } \mathrm{A}=\left(\begin{array}{cc}
1 & \mathrm{a}_{12} \\
\mathrm{a}_{21} & 1
\end{array}\right) \quad \mathrm{B}=\left(\begin{array}{ll}
1 & 0 \\
0 & 1
\end{array}\right) \text {,the unknown parameters of all SVAR models can be estimated,We }
$$

calculate and get the result: $\mathrm{A}=\left(\begin{array}{cc}1 & 23.70 \\ -17.65 & 1\end{array}\right)$,then

$$
\begin{aligned}
& \left(\begin{array}{l}
\Delta \ln W W P \\
\Delta \operatorname{lnPGDP}
\end{array}\right)=\left(\begin{array}{l}
-23.70 \Delta \ln \mathrm{PGDP} \\
17.65 \Delta \ln W W \mathrm{P}
\end{array}\right)+\left(\begin{array}{cc}
2.5660 & 6.2019 \\
5.0267 & -14.2813
\end{array}\right)\left(\begin{array}{l}
\Delta \ln W W \mathrm{P}(-1) \\
\Delta \ln \mathrm{PGDP}(-1)
\end{array}\right) \\
& +\left(\begin{array}{rr}
-4.1671 & -11.9707 \\
5.2026 & 13.7902
\end{array}\right)\left(\begin{array}{l}
\Delta \ln W W P(-2) \\
\Delta \ln P G D P(-2)
\end{array}\right)+\left(\begin{array}{rl}
-19.4772 & 21.5931 \\
14.1988 & -19.2580
\end{array}\right)\left(\begin{array}{l}
\Delta \ln W W P(-3) \\
\Delta \operatorname{lnPGDP}(-3)
\end{array}\right)+\left(\begin{array}{l}
1.2694 \\
3.5920
\end{array}\right)+\left(\begin{array}{l}
u_{11} \\
u_{21}
\end{array}\right)
\end{aligned}
$$

The SVAR model reflects the relationship between wastewater pollution and economic growth. Then we use the impulse response function to analyze the effect on the environment caused by of the shock of economy, and the effect on economy caused by the shock of the environment. In addition, we use variance decomposition to analyze the contribution of structural shocks to the endogenous variables.

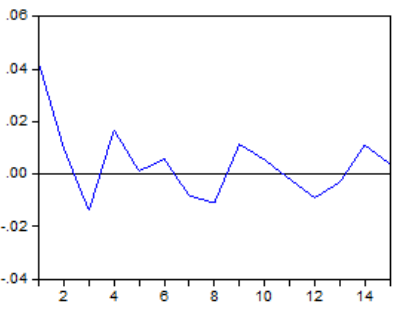

Figure 2

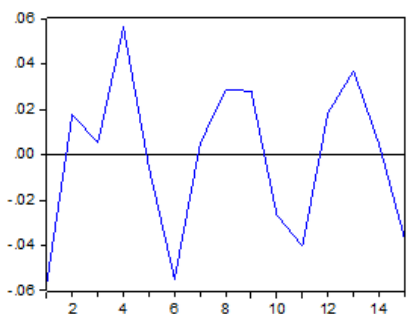

Figure 3

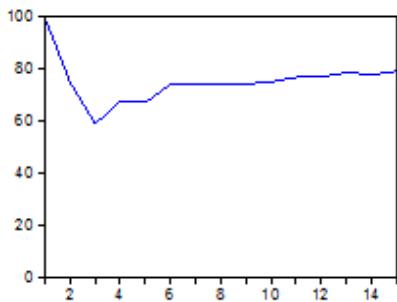

Figure 4

Figure 2: response of water pollution growth to per GDP growth

Figure 3: response of per GDP growth to water pollution growth

Figure 4: variance contribution rate of economic growth to water pollution growth

In figure2, we can see that when giving a shock of per capita GDP growth, it brings the increase of water pollution, and reaches a maximum in the fifth period, and water pollution growth rate will be reduced to the minimum in the sixth period, then increase and reduce again, it has been in fluctuation, So that the per capita income has very long period impact on the water pollution. In Figure3, we can see that when giving a shock of water pollution growth, it also bring economic growth decreases, and reaches minimum in the third period, and then the economic growth rate increases a little, and then quickly decreases again, and so on, also it has been in fluctuation. So that water pollution for economic growth has very long period effects. In Figure 4, we can see the percent of water pollution growth variance due to per capita GDP growth stabilized at around about 
$70 \%$ after 8th period, It shows that economic growth on the increase of the water pollution has very big effect.

\section{Results and conclusion}

From the results of the impulse response function and the variance decomposition of the SVAR model, the impact of economic growth on environmental pollution is along-term fluctuating, and environmental pollution also has a long-term impact on the economy. From the results of RVC, the contribution rate of economic growth to water pollution is $70 \%$, which indicates that the environmental pollution brought by the economy is huge. The second industry accounts for a large proportion in Hubei's current economic production, and its emission intensity to pollutants is relatively large, which has destroyed the harmony of economy and environment. Hubei province needs to change the traditional mode of industrialization. Otherwise, the rapid economic growth will have far-reaching impact on the environment for a period of time. The government needs to adjust the industrial structure reasonably and change the way of economic growth to promote the harmonious development of the economy and the environment.

\section{References}

[1] Research of the relationship between environmental pollution and economic growth based on SVAR model. Huan Liu,Qiao Fang, Shuang Wang. Business and Globalization, 2013,1.

[2] FDI, economic growth and environmental pollution: an empirical analysis based on SVAR model. Shang Guan Xu ming. Ecological Economy.2014,10.

[3] Data analysis and application of Eviews. Yi Danhui. Beijing people's University Press, 2008.

[4] The perspective of time series analysis of Financial Econometrics. Zhang Cheng si.Beijing people's University Press. 2012.

[5] Method and modeling of econometric analysis. Gao Tiemei.Tsinghua university Press.2006. 